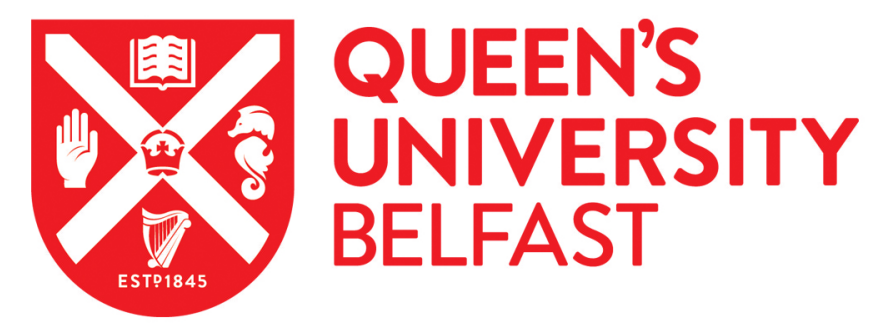

\title{
Healthcare use, costs and quality of life in patients with end-stage kidney disease receiving conservative management: results from a multi-centre observational study (PACKS)
}

Phair, G., Agus, A., Normand, C., Brazil, K., Burns, A., Roderick, P., Maxwell, A. P., Thompson, C., Yaqoob, M., \& Noble, H. (2018). Healthcare use, costs and quality of life in patients with end-stage kidney disease receiving conservative management: results from a multi-centre observational study (PACKS). Palliative Medicine. https://doi.org/10.1177/0269216318775247

\section{Published in:}

Palliative Medicine

\section{Document Version:}

Peer reviewed version

Queen's University Belfast - Research Portal:

Link to publication record in Queen's University Belfast Research Portal

\section{Publisher rights}

(C) 2018 The Authors.

This work is made available online in accordance with the publisher's policies. Please refer to any applicable terms of use of the publisher.

\section{General rights}

Copyright for the publications made accessible via the Queen's University Belfast Research Portal is retained by the author(s) and / or other copyright owners and it is a condition of accessing these publications that users recognise and abide by the legal requirements associated with these rights.

Take down policy

The Research Portal is Queen's institutional repository that provides access to Queen's research output. Every effort has been made to ensure that content in the Research Portal does not infringe any person's rights, or applicable UK laws. If you discover content in the

Research Portal that you believe breaches copyright or violates any law, please contact openaccess@qub.ac.uk. 


\title{
Healthcare use, costs and quality of life in patients with
}

\author{
end-stage kidney disease receiving conservative
}

management: results from a multi-centre observational

study $($ PACKS).

KEYWORDS: Chronic Kidney Disease, Conservative Management, Costs, Economics,

Glenn Phair $^{1}$, Dr Ashley Agus ${ }^{1}$, Professor Charles Normand ${ }^{2}$, Professor Kevin Brazil ${ }^{3}$, Dr Aine

Burns $^{4}$, Professor Paul Roderick ${ }^{5}$, Professor Alexander P. Maxwell ${ }^{3,6}$, Mr Colin Thompson ${ }^{7}$ Professor Magdi Yaqoob ${ }^{8,9}$, Dr Helen Noble ${ }^{3}$

${ }^{1}$ Northern Ireland Clinical Trials Unit

${ }^{2}$ Trinity College Dublin

${ }^{3}$ Queen's University Belfast

${ }^{4}$ Royal Free Hospital

${ }^{5}$ University of Southampton

${ }^{6}$ Belfast City Hospital

${ }^{7}$ Northern Ireland Kidney Patient Association

${ }^{8}$ The Royal London Hospital

${ }^{9}$ Queen Mary University of London

\section{Corresponding author}

Glenn Phair, Northern Ireland Clinical Trials Unit, $1^{\text {st }}$ Floor Elliott Dynes, Royal Group of Hospitals, Grosvenor Road, Belfast BT12 6BA

PACKs Health Service Use Analysis 


\begin{abstract}
Background: Previous research has explored the cost of providing renal replacement therapies in patients with end-stage kidney disease and their quality of life. This is the first study to examine the healthcare costs of patients receiving conservative care without dialysis for end-stage kidney disease. This alternative to dialysis is an option for patients who prefer a supportive and palliative care approach.
\end{abstract}

Aims: Descriptive cost and quality of life analyses alongside a United Kingdom based multi-centre observational study in patients receiving conservative management for end-stage kidney disease.

Design: Health service use was recorded up to 12 months after making the decision to receive conservative management. Mean costs were calculated for each 3-month time period. The annual cost was calculated two ways; using only patients with complete cost data, and by using all available data weighted by the number of patients at each time point.

Setting: Forty-two patients who opted for conservative management over dialysis were recruited.

Results: Mean costs were; $£ 1622$ (0-3 months), £1008 (3-6 months), £554 (6-9 months) and $£ 2626$ (912 months). Mean annual cost based on complete data $(n=8)$ was $£ 5511$, and the weighted mean annual cost was $£ 5620$.

Conclusions: The importance of this study is twofold. First, it provides substantive new information for health and social care planning of conservative management by demonstrating where demand exists for services, in both the UK and other countries with a comparable health service structure. Second, methodologically it indicates that it is feasible to collect service use data directly from this patient population. 


\section{Key Statements}

\section{What is already known about the topic?}

- End-stage kidney disease (ESKD) is associated with significantly increased morbidity and premature mortality, with evidence suggesting that offering dialysis to frail patients with comorbidities may be of little benefit to quality or quantity of life.

- Patients may forgo dialysis in order to receive conservative management instead: a supportive approach to care. Costs associated with this have not been previously captured.

\section{What this paper adds}

- First study to examine health service use and costs alongside quality of life in patients receiving conservative management for ESKD.

- The prospective nature of the resource use logs meant increased transparency with regard to resource allocation, providing guidance as to where demands for healthcare resources were generated.

- Conservative management of ESKD is likely to be considerably less expensive than dialysis.

\section{Implications for practice, theory or policy}

- Provides information for healthcare planning for patients with ESKD in the UK and countries with a comparable health service structure.

- Larger studies could identify predictors of resource use and costs. Comparison between dialysis and conservative management in terms of costs and quality of life is required.

- Resource logs used can be adapted for similar studies. Understanding the costs of such services enables commissioners to make more informed decisions. 


\section{Introduction}

End-stage kidney disease (ESKD) is a life-limiting disease associated with significantly increased morbidity and premature mortality. Providing dialysis to a growing, frail population with ESKD is a challenge faced by many countries particularly those with poor economic resources [1]. ESKD consumes approximately $2 \%$ of the UK's National Health Service (NHS) annual budget [2] and hospital-based haemodialysis costs up to $£ 35,000$ per person annually [3]. In the United States, hospital-based dialysis costs up to US\$90,000 per person per year [4]. Evidence is emerging that offering dialysis to vulnerable, frail patients with additional comorbidities may be of little benefit in terms of quality of life (QOL) or prolonging survival [5][6][7][8].

An alternative to dialysis is conservative management (also known as supportive or palliative care), which offers a supportive approach to care delivered by a skilled multi-professional team [9] for "prevention and relief of suffering by means of early identification and impeccable assessment and treatment of pain and other problems" [10]. Patients have the option to choose this pathway over dialysis. In addition, The Renal Physicians Association has updated practice guidance upholding the rights of patients not to commence dialysis [11].

In a study examining the use of conservative care via hospice services in dialysis patients in the USA, there was a reduction in the number of hospital visits compared to those who did not use hospices [12]. In contrast, patients with ESKD in the UK do not have easy access to hospice services.

In the KDIGO 'Controversies Conference on Supportive Care in Chronic Kidney' [10], conferees recommended supportive and palliative care be recognised as an important component of education for medical professionals in this field. For optimal delivery, appropriate patients should be identified with subsequent care based on need rather than solely on survival estimates. They also highlighted the importance of robust economic evaluation of kidney supportive care to inform resource allocation decisions within healthcare organisation. Research is needed into the costs and benefits of dialysis versus conservative kidney management for planning purposes and to aid decisions by patients and their families [13], and there is a lack of data on the costs of providing conservative care. To do so 
requires information on the patient experience with regard to resource use when the conservative care approach is followed. This is important from a decision-making perspective in helping to inform treatment decisions and commissioning healthcare services. We were unable to find other studies that looked at resource use and costing in this population.

The Palliative Care in Chronic Kidney Disease (PACKs) study [14] was an observational study measuring several parameters including QOL, satisfaction with decision-making [15], costs of care, cognition, frailty and performance in patients with advanced chronic kidney disease managed without dialysis. The impact on carers in terms of burden and QOL was also studied. The study did not seek to compare treatment costs of dialysis versus conservative management, rather it aimed to explore the health and social care service use and quality of life of patients with ESKD who opt for conservative management and estimate costs to the NHS.

\section{Methods}

Study design

The PACKs study [15] was a multi-centrestudy which recruited 42 participants with ESKD from nine renal units in the UK: five in Northern Ireland; four in England. Participants were eligible if they had stage 5 chronic kidney disease with estimated glomerular filtration rate (eGFR) $\leq 15 \mathrm{~mL} / \mathrm{min} / 1.73 \mathrm{~m}^{2}$ and a confirmed decision for management of kidney failure without dialysis. The study was approved by the Office for Research Ethics Committees Northern Ireland. The Northern Ireland Clinical Trials Unit (NICTU) co-ordinated the study and undertook the analysis.

\section{Data collection}

The economic analysis was undertaken from the perspective of the NHS and Personal Social Services (PSS) in line with the current recommendations set out by the National Institute for Health and Care Excellence [16] with additional data collected on carers paid for privately. Patients' use of health and social care services was measured over the study period using service use logs specifically developed for the PACKS study. Logs were provided at the baseline clinic visit by a research nurse, who 
provided guidance on completion. Patients were asked to record contacts with healthcare professionals in the community, hospital service use, and formal care visits. They were asked to record if hospital clinics and admissions were related to their disease. Estimates of the duration of GP and hospital clinic appointments were also requested. Neither costs of informal care nor prescription use were included in the analysis. The logs were designed for self-completion by the patient but, if preferred, they could be completed by their carer or nurse. This was recorded on the log.

It was not feasible to validate patient reported data from administrative databases. Where fields on the returned logs were left blank it was assumed that the patient did not use this particular service. In cases where optional "Yes" and "No" checkboxes were left blank it was also assumed that these services were not used.

Individual-level health and social care service use was combined with unit costs to estimate costs for each participant. Unit costs were obtained from publicly available sources and set at 2015-2016 prices. These were the NHS Schedule of Reference Costs for hospital resources and the Unit Costs of Health and Social Care for general practice services [17][18] (Table 1). Descriptive statistics were used to summarise resource use and associated costs from 0-3, 3-6, 6-9 and 9-12 months, categorised according to community, hospital and carer services. The annual cost for each category was a weighted average based on the mean costs and number of patients at each time period. The total annual cost was calculated by summing the annual costs for each category.

Patients recruited later in the study were unable to complete logs at every time point due to study closure. Their data was censored as they had less than full follow-up in the study.

Health-related quality of life (HRQoL) was measured at baseline, 3, 6, 9 and 12 months using the generic instrument the EQ-5D-5L [19], and the EQ-5D-5L value set for England was used to obtain utility scores based on the responses [20]. This has been shown to be a valid instrument for the measurement of health status in renal patients [21].

Table 1 Unit Costs ( $£$ UK) of health and social care services. 


\begin{tabular}{|c|c|c|}
\hline Resource Items & Unit Cost & Source \\
\hline \multicolumn{3}{|c|}{ Community Health Services } \\
\hline GP surgery Visit & $£ 36.00$ & $\begin{array}{l}\text { Unit Costs of Health and Social } 2016 \text { p.145. } 9.22 \mathrm{~min} \\
\text { consultation (with qualifications) }\end{array}$ \\
\hline GP telephone consultation & $£ 14.40$ & Unit Costs of Health and Social 2016 p.147. \\
\hline GP home Visit & $£ 83.16$ & $\begin{array}{l}\text { Unit Costs of Health and Social } 2016 \text { p.145. } 9.22 \text { min } \\
\text { consultation \&12 min travel time at } £ 236 \text { per hour- (time } \\
\text { based on PSSRU 2015) }\end{array}$ \\
\hline GP out of hours visit & $£ 83.16$ & $\begin{array}{l}\text { Unit Costs of Health and Social } 2016 \text { p.145. } 9.22 \text { min } \\
\text { consultation } \& 12 \text { min travel time at } £ 236 \text { per hour (time } \\
\text { based on PSSRU 2015) }\end{array}$ \\
\hline GP Nurse surgery visit & $£ 11.11$ & $\begin{array}{l}\text { Unit Costs of Health and Social } 2016 \text { p.143. Cost per hour } \\
\text { face to face } £ 43 \text {, based on } 15.5 \text { min consultation }\end{array}$ \\
\hline $\begin{array}{l}\text { GP Nurse telephone } \\
\text { consultation }\end{array}$ & $£ 6.10$ & Unit Costs of Health and Social 2016 p.147. \\
\hline Social Worker & $£ 79.00$ & Unit Costs of Health and Social 2016 p.156 (per hour) \\
\hline NHS Physiotherapist & $£ 45.00$ & Unit Costs of Health and Social 2016 p.185 (per hour) \\
\hline District nurse & $£ 44.00$ & Unit Costs of Health and Social 2016 p.142 (per hour) \\
\hline Specialist nurse & $£ 44.00$ & $\begin{array}{l}\text { Unit Costs of Health and Social } 2015 \text { p.172. Uprated from } \\
2015 \text { using HCHS inflation index [19] }\end{array}$ \\
\hline Chiropodist & $£ 32.00$ & Unit Costs of Health and Social 2016 p.136 (per hour) \\
\hline \multicolumn{3}{|l|}{ Hospital Services } \\
\hline Attendance at $\mathrm{A} \& \mathrm{E}$ & $£ 238.00$ & Unit Costs of Health and Social 2016 p.95 \\
\hline Outpatient attendance & $£ 135.00$ & Unit Costs of Health and Social 2016 p.95 \\
\hline Inpatient stay & $£ 397.00$ & Unit Costs of Health and Social 2016 p.95 \\
\hline Residential care home & $£ 519.00$ & $\begin{array}{l}\text { Unit Costs of Health and Social } 2016 \text { p.26. Mean cost per } \\
\text { week- private residential care home. } £ 74.14 \text { per night. }\end{array}$ \\
\hline Hospital clinics & $£ 136.00$ & $\begin{array}{l}\text { NHS Reference costs 2015/2016. Medical specialist } \\
\text { palliative care (SD04A) }\end{array}$ \\
\hline \multicolumn{3}{|l|}{ Carer Services } \\
\hline NHS Care Worker & $£ 18.00$ & Unit Costs of Health and Social 2016 p.160 (per hour) \\
\hline
\end{tabular}




\section{Results}

Forty-two patients were recruited between March 2015 and May 2016. Figure 1 shows the retention and drop out of participants. There were 42 patients with baseline data then $24,16,13$ and 10 at each 3 month interval. Reasons for dropout included death and withdrawal of consent. Additionally, follow-up on some participants was limited by end-of-study censoring.

Patient characteristics at baseline are summarised in Table 2. The mean age of participants was 79.8 years; $59.5 \%$ (25/42) were female; and 47.6\% (20/42) were widowed. Mean eGFR at baseline was $12.47 \mathrm{~mL} / \mathrm{min} / 1.73 \mathrm{~m}^{2}$. There were eight patients recruited who died before the study ended: four of these before the first follow-up visit. At all time points the majority of patients received staff assistance completing the log. 


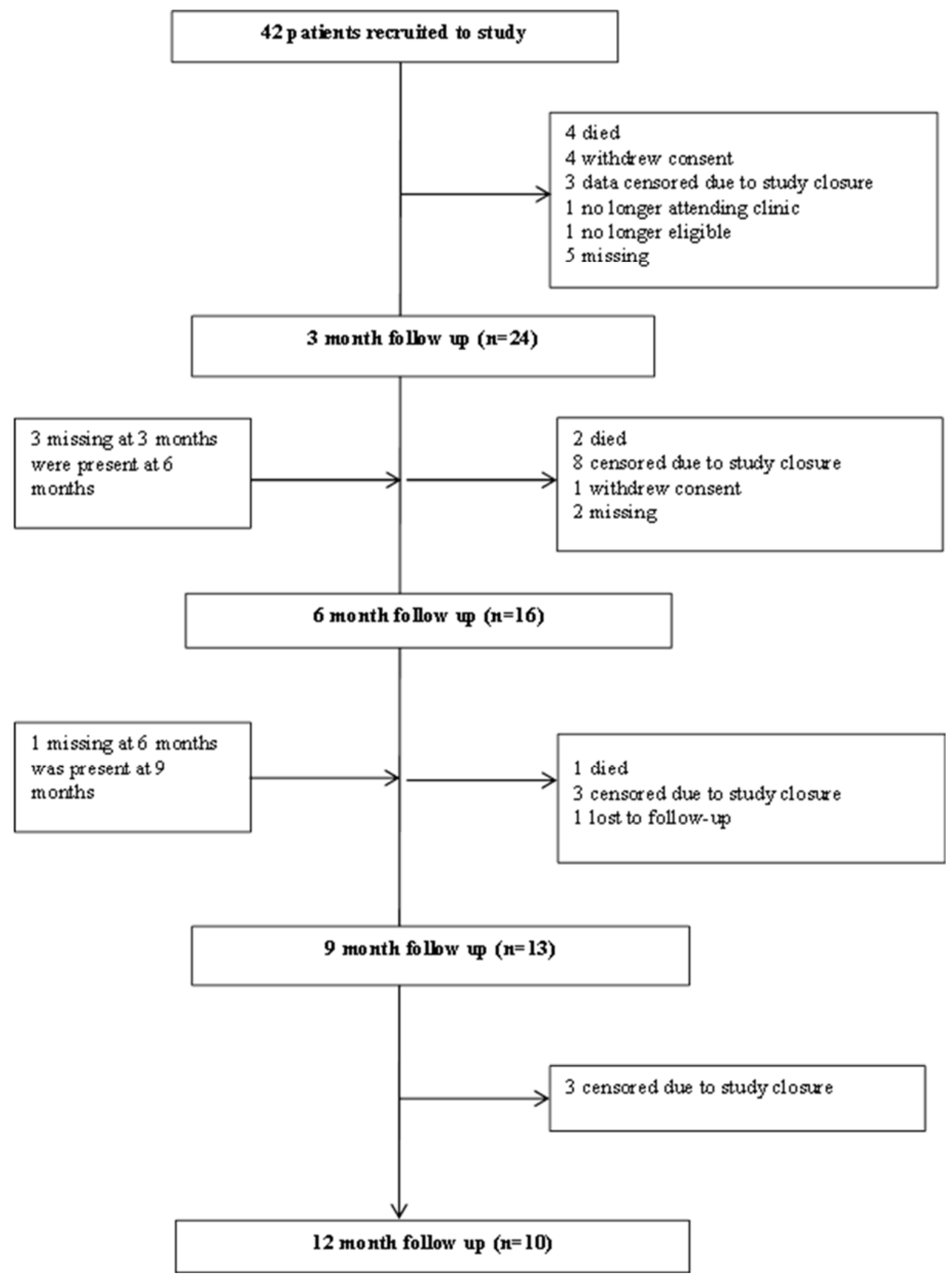

Figure 1 Flow Chart showing patients' retention and drop out over the study period.

PACKs Health Service Use Analysis 
Table 2 Baseline characteristics of patients in the PACKs study

\begin{tabular}{|c|c|}
\hline & $\begin{array}{l}\text { Baseline }(n=42) \\
n / \text { mean }\end{array}$ \\
\hline Age (years; SD) & $79.75(8.06)$ \\
\hline $\begin{array}{lll}\text { Gender } & & \\
& \bullet & \text { Male } \\
& \bullet & \text { Female } \\
\end{array}$ & $\begin{array}{l}17 \\
25 \\
\end{array}$ \\
\hline $\begin{aligned} \text { Marital Status } & \\
\bullet & \text { Single } \\
\bullet & \text { Married } \\
\bullet & \text { Divorced } \\
\bullet & \text { Widowed } \\
\bullet & \text { Other }\end{aligned}$ & $\begin{array}{l}3 \\
14 \\
2 \\
20 \\
3\end{array}$ \\
\hline $\begin{array}{ll}\text { Race } & \\
& \bullet \text { White } \\
& \bullet \text { Asian/Asian British } \\
& \text { - Black/African/Caribbean/Black British } \\
& \text { Other }\end{array}$ & $\begin{array}{l}31 \\
6 \\
4 \\
1\end{array}$ \\
\hline Estimated Glomerular Filtration Rate $\left(\mathrm{mL} / \mathrm{min} / 1.73 \mathrm{~m}^{2} ; \mathrm{SD}\right)$ & $12.47(3.22)$ \\
\hline
\end{tabular}

Use of health services

Total costs in each 3-month period by service type - carer, community and hospital- are presented in Table 3, as well as the weighted one year average. Supplementary Table 1 gives a more detailed breakdown of the exact numbers of services used in each time period and their corresponding costs. The overall total costs per 3-month period were highest at 9-12 months, totalling £2626, of which $42 \%$ was accounted for by hospital and residential admissions. This was almost five times the total cost in the 6-9 month period. Figure 2 (displaying data from Table 3) shows the total costs for each period according to service type. Figure 2 illustrates that the highest proportion of costs were associated with clinic visits and hospital admissions in the 0-3 and 9-12 month periods.

The rightmost bars of Figure 2 show the total one year cost for eight study participants who had complete cost data (i.e. completed all resource logs in the study) and a weighted average of costs over the 12 -month period. In the former cohort the total annual cost per patient was $£ 5510,57 \%$ of which was carer costs. In the latter, the weighted average was comparable at $£ 5620$, but hospital costs made up $55 \%$ of the total.

PACKs Health Service Use Analysis 
In one patient who died between $0-3$ months, resource use was much higher than average: $£ 3125$ for the 3 months from baseline. In one of the patients who died before their 6-month visit the cost of their resource use was $£ 6819$ and $£ 2595$ for 0-3 and 3-6 months, respectively. In both cases these higher expenditures were driven primarily by hospital associated costs.

Table 3 Mean health service total costs (£UK) by service type for patients in the PACKs study. Values are means $(95 \% \mathrm{CI})$.

\begin{tabular}{|c|c|c|c|c|c|c|}
\hline & $\begin{array}{l}0-3 \\
\text { months } \\
(n=24)\end{array}$ & $\begin{array}{l}3-6 \\
\text { months } \\
(n=16)\end{array}$ & $\begin{array}{l}6-9 \\
\text { months } \\
(n=13)\end{array}$ & $\begin{array}{l}9-12 \\
\text { months } \\
(n=10)\end{array}$ & $\begin{array}{l}1 \text { Year } \\
\text { Data; } \\
\text { Complete } \\
(n=8)\end{array}$ & $\begin{array}{l}1 \text { Year } \\
\text { Data; } \\
\text { Weighted }\end{array}$ \\
\hline & $\begin{array}{l}\text { Mean } \\
\text { Cost (f) } \\
(95 \% \text { CI })\end{array}$ & $\begin{array}{l}\text { Mean } \\
\text { Cost (f) } \\
(95 \% \text { CI })\end{array}$ & $\begin{array}{l}\text { Mean } \\
\text { Cost (f) } \\
(95 \% \text { CI })\end{array}$ & $\begin{array}{l}\text { Mean } \\
\text { Cost (f) } \\
(95 \% \text { CI })\end{array}$ & $\begin{array}{l}\text { Mean Cost } \\
\text { (f) } \\
(95 \% \text { CI })\end{array}$ & $\begin{array}{l}\text { Mean Cost } \\
\text { (f) }\end{array}$ \\
\hline $\begin{array}{l}\text { Carer Cost } \\
\text { (Total) }\end{array}$ & $\begin{array}{l}423.75(- \\
114.21 \\
961.71)\end{array}$ & $\begin{array}{l}465.75(- \\
296.41, \\
1227.91)\end{array}$ & $\begin{array}{l}167.70(- \\
65.03, \\
400.43)\end{array}$ & $\begin{array}{l}968.40(- \\
484.28, \\
2421.08)\end{array}$ & $\begin{array}{l}3120.75(- \\
1835.15 \\
8076.65)\end{array}$ & 1872.13 \\
\hline $\begin{array}{l}\text { Community } \\
\text { Cost (Total) }\end{array}$ & $\begin{array}{l}135.85 \\
(26.81 \\
244.90)\end{array}$ & $\begin{array}{l}212.36 \\
(57.79, \\
366.93)\end{array}$ & $\begin{array}{l}147.04 \\
(37.61, \\
256.47)\end{array}$ & $\begin{array}{l}152.50 \\
(30.20, \\
274.81)\end{array}$ & $\begin{array}{l}868.83 \\
(28.68, \\
1708.99)\end{array}$ & 640.93 \\
\hline $\begin{array}{l}\text { Hospital Cost } \\
\text { (Total) }\end{array}$ & $\begin{array}{l}1062.50 \\
(221.03, \\
1903.97)\end{array}$ & $\begin{array}{l}329.50 \\
(19.35, \\
639.65)\end{array}$ & $\begin{array}{l}239.31 \\
(101.65, \\
376.97)\end{array}$ & $\begin{array}{l}1504.90(- \\
35.80, \\
3045.60)\end{array}$ & $\begin{array}{l}1521.38 \\
(350.73 \\
2692.02)\end{array}$ & 3106.80 \\
\hline $\begin{array}{l}\text { GRAND } \\
\text { TOTAL }\end{array}$ & $\begin{array}{l}1622.10 \\
(646.00, \\
2598.21)\end{array}$ & $\begin{array}{l}1007.61 \\
(198.98, \\
1816.24)\end{array}$ & $\begin{array}{l}554.05 \\
(281.91, \\
826.19)\end{array}$ & $\begin{array}{l}2625.80 \\
(455.46, \\
4796.15)\end{array}$ & $\begin{array}{l}5510.96 \\
(261.03, \\
10760.89)\end{array}$ & 5619.86 \\
\hline
\end{tabular}




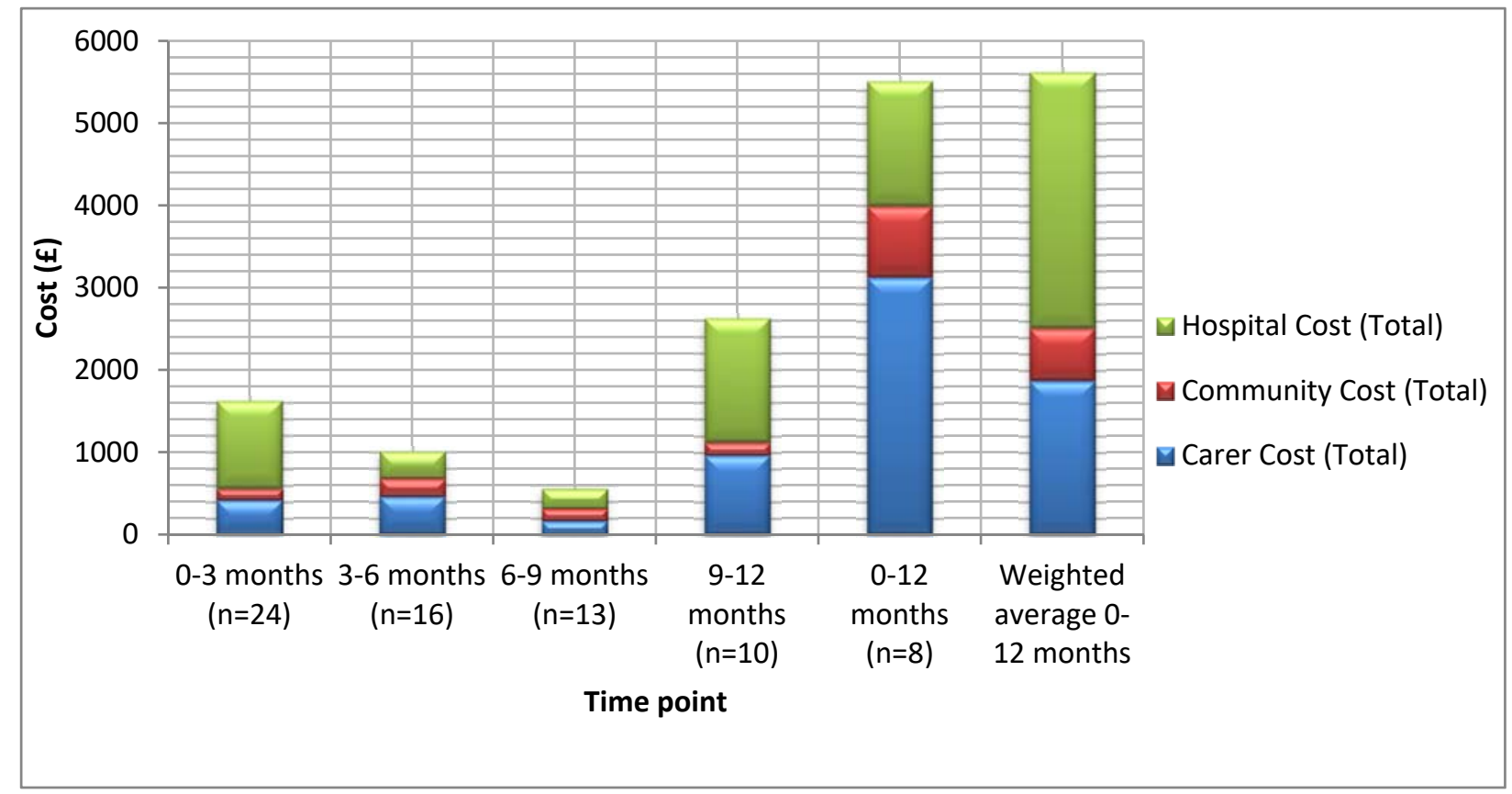

Figure 2 Hospital, Community and Carer costs (£UK) for each period from patients in the PACKs study

\section{Health outcomes}

Table 4 shows the HRQoL of patients from baseline to 12 months using the EQ-5D-5L. The changes in means are illustrated in Figure 3 and demonstrates that the mean HRQoL was highest at 6 months (0.79) and lowest at 12 months (0.67) in those remaining in the study.

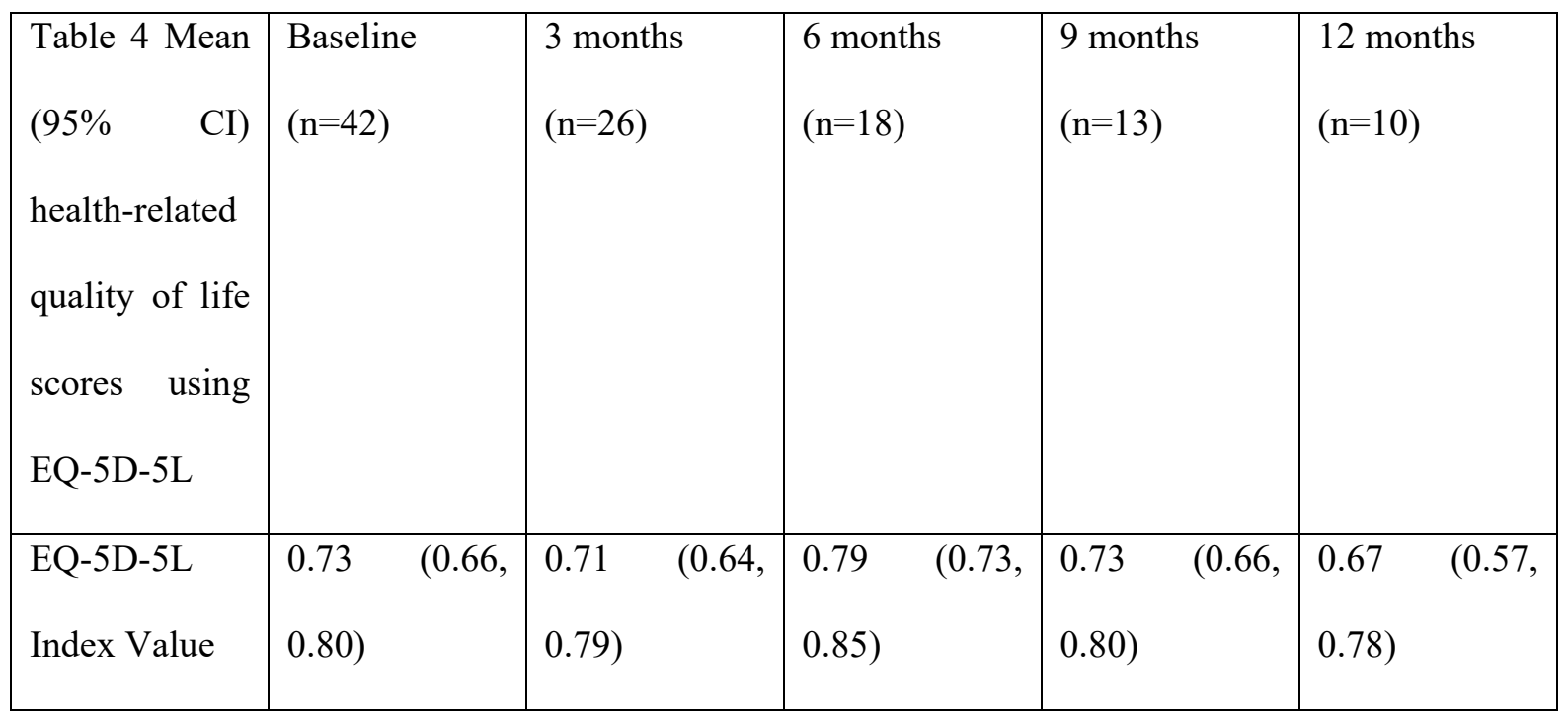




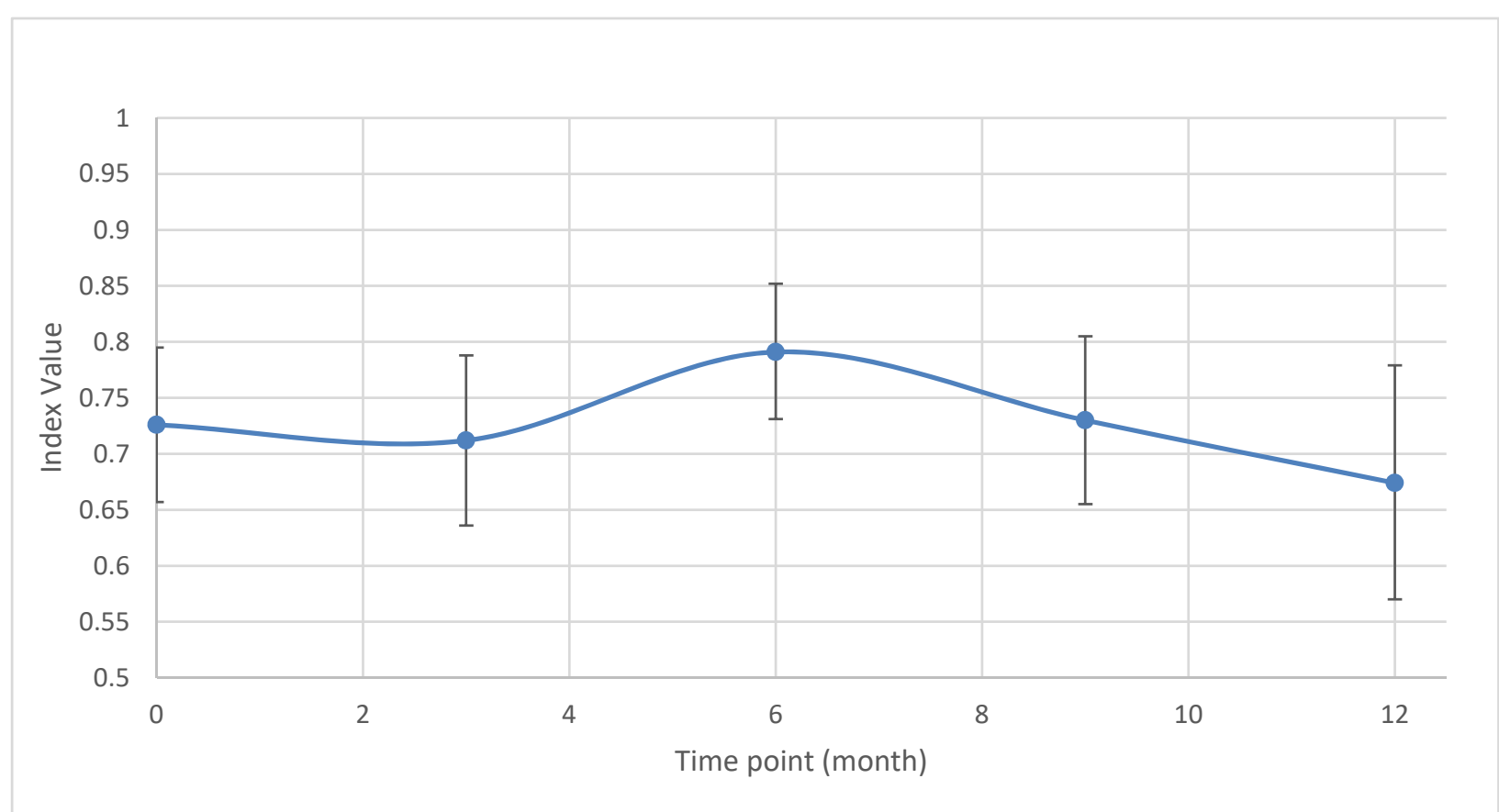

Figure 3 Patient EQ-5D-5L index scores and 95\% CI in 3 month increments from baseline to 12 months

\section{Discussion}

\section{Main Findings}

This is the first study to examine health service use,costs and associated HRQoL in patients receiving conservative management for ESKD, now established as an alternative to maintenance dialysis. Barriers exist which impact on recruiting participants with ESKD to renal research studies including frailty, fatigue, prognostic uncertainty, reluctance to discuss end-of-life and impending death [13]. This has led to poor knowledge of this population which this paper goes some way to address.

The average health service cost in the first year of the study (from the decision to receive conservative management and recruitment) was $£ 5619$, approximately one sixth of the cost of dialysis in the UK [3]. We recognise that if we had included a population of dialysis patients eGFR would have fallen 
further prior to commencement of dialysis treatment, meaning the comparison of one year costs may not be like for like. That aside, the costings can be interpreted in light of this fact. The data shows that costs were highest in the first and last periods, arguably reflecting higher service use linked with the set-up and planning phase, then much higher service use associated with a small number of patients becoming more frail and dependent. The weighted mean estimated hospital care as the largest expenditure, is in contrast to the estimate using patients with complete data where carers accounted for the majority. This was largely due to two patients receiving multiple daily home visits. We would emphasise that the decision to undergo dialysis or not by patients and clinicians must not be based solely on the cost of care, but a host of factors, some specific to the individual. However, this study highlights the importance of considering whether a patient will receive a sufficient gain in survival and/or QOL to justify the higher costs of dialysis compared to conservative management. On average HRQoL declined over time but this was not a substantial decrease. We suggest that the higher service use observed in the 9-12 month time period may reflect some deterioration in health state associated with progression of ESKD, the debilitating nature of the disease and increased frailty but requires further.study. Use of services was lowest between 6-9 months, following the time point when patient EQ-5D-5L scores were at their peak, possibly showing a causal fall in service demand with higher HRQoL.

\section{Strengths and limitations}

Cost estimates were highly variable due to the small numbers of patients involved and should be interpreted with caution. Nevertheless, this observational study of clinical practice demonstrates that conservative management of ESKD is likely to be considerably less expensive than chronic dialysis [3].

The main reasons for dropout in the study included death and data censoring due to study closure. This suggests that the resource use logs and the EQ-5D-5L were acceptable and the majority of patients left in the study did fill them in.

This study included data from nine renal units in the UK. Since most UK renal units offer conservative management or supportive and palliative care services for ESKD it is likely that the costs 
identified are broadly similar in each UK region. However, only a minority of UK regions have funding specifically for conservative management [13]. A larger study could identify the predictors of specific resource use and associated costs using multiple regression methods, looking at factors like disease severity, comorbidities and demographic data. Patients were all recruited as they made a decision not to undergo dialysis, and whilst they have this in common each individual would have been on a different trajectory in terms of their disease progression, how it affected them and their resource use. Therefore, focusing analysis on arbitrary 3-month time periods for patients is not comparing like with like but merely a window in time from when a choice was made. Ideally patients would be followed from time of referral through to death, measuring resource use along the way, but this was not a feasible option. These time periods were chosen to capture as much data as possible as patients were expected to drop out due to death and deteriorating health.

Collecting data on prescription medication use would also be useful if further studies of patients with ESKD to establish which drugs are prescribed and the contribution of medication to total costs. Extended follow-up period would be beneficial to capture longer term costs, to establish survival rates and how costs change as people approach death. The relationship between length of survival and costs could be analysed.

\section{What this study adds}

Descriptive cost analyses of this nature identify and measure the resource use that this population of patients incur. Thus, the economic burden of given health problems on the overall population can be assessed. The design of the resource use log used in the study meant most health and social care services used by patients were captured. This "bottom-up" approach measures health care utilisation data on a patient-level basis. The prospective nature of the service use log meant it could be filled in when visits occurred, rather than relying on recall at follow-up visits. Also, by administering the log in 3-month increments it is easier to see when costs were incurred. The end result is transparency with regard to resource allocation, providing guidance as to where most demand is generated. Given that ESKD care is estimated to consume $2 \%$ of the annual NHS budget it is important to know what specific services require funding [2]. 
Future studies could include direct comparison between dialysis and conservative management in terms of both costs and HR QOL, and a trial has begun with ESKD patients randomised to preparation pathways for responsive management or renal dialysis [22].

Using discrete choice experiments in this population would give an insight into the attributes important to patients in decision-making. This shows where patients are willing to make trade-offs between, for example, changes to duration of life versus QOL, as well as how the burden of treatment affects the treatment chosen. A literature review of discrete choice experiments in nephrology [23] reported attributes such as treatment timing, weekly hospital visits, life expectancy and type of care.

The results of the PACKs study [16,17] will also be of interest to patient support groups who are active in making relevant stakeholders aware of the types of services required to treat ESKD and helping these develop. As well as this, many provide support to kidney units in the form of financial assistance for facilities but also to fund staff for caring purposes.

\section{Conclusion}

This is the first study to prospectively measure the health and social care use and costs of patients with ESKD who opt for conservative management. The study also provides valuable information for health and social care planning for patients with ESKD in both the UK and other countries with a comparable health service structure. Furthermore, it indicates that it is feasible to use self-report methods to collect service use and associated HRQoL from this patient population within a study setting.

\section{Acknowledgements}

Study funded by the National Institute for Health Research and the Health and Social Care Research and Development Division of the Public Health Agency Office Northern Ireland NIHR (CDV/4872/13). Thanks are given to service users of the Northern Ireland Kidney Patient Association, Northern Ireland and the Kidney Research and Education Initiative, London who have assisted in the development of the study protocol.

Also acknowledged are staff of the Northern Ireland Clinical Trials Unit.

\section{Authors' contributions}

$\mathrm{HN}$ and AA conceived and designed the health economic component of PACKs. HN obtained the funding. All authors made a substantial contribution to the protocol development. GP performed the 
analysis. All authors interpreted the data. GP wrote the first draft of the manuscript and all authors critically reviewed it for important intellectual content and approved it. All authors vouch for the integrity, accuracy, and completeness of the data.

\section{Funding}

The author(s) disclosed receipt of the following financial support for the research, authorship and/or publication of this article: This work was supported by Research Trainees Coordinating Centre (Grant/Award Number: R464NUR).

\section{Declaration of conflicts of interest}

The author(s) declared no potential conflicts of interest with respect to the research, authorship and/or publication of this article.

\section{Research ethics and patient consent}

The study was approved by the Office for Research Ethics Committees Northern Ireland $(14 / \mathrm{NI} / 0057)$.

\section{Data management and sharing}

Data available upon request.

\section{Acknowledgements}

The authors thank the patients and carers of the Northern Ireland Kidney Patient Association, Northern Ireland, who have assisted in the development of the PACKS study and are assisting with dissemination of findings.

Trial registration: ISRCTN06857980. Registered 01/07/2014.

\section{References}

1. Naicker S. Nephrology in Africa - challenges of practice in resource-limited environment. Clinical Nephrology, 2016; 86 (13):84-89.

2. El Kossi M, Kasarawa Bello A, Hamer R \& El Nahas A. Chronic kidney disease - prevention of progression and of cardiovascular complications. In: Goldsmith D, Jayawardene S \& Ackland P (eds). ABC of Kidney Disease. Blackwell Publishing, Oxford. 2007; pp. 11-14.

3. Baboolal K, McEwan P, Sondhi S et al. The cost of renal dialysis in a UK setting-a multicentre study. Nephrology Dialysis Transplantation, 2008; 23 (6): 1982-1989.

4. Karopadi, AN. Cost of peritoneal dialysis and haemodialysis across the world. Nephrology Dialysis Transplantation, 2013. 28: 2553-2569.

5. Murtagh FE, Addington-Hall JM \& Higginson IJ. End-stage renal disease: a new trajectory of functional decline in the last year of life. Journal of the American Geriatric Society, 2011; 59(2):304-8.

6. Canaud B, Tong L, Tentori F et al. Clinical practices and outcomes in elderly hemodialysis patients: results from the Dialysis Outcomes and Practice Patterns Study (DOPPS). Clinical Journal of the American Society of Nephrology, 2011; 6:1651-1662.

7. Tamura MK, Covinsky KE, Chertow GM et al: Functional status of elderly adults before and after initiation of dialysis. New England Journal of Medicine, 2009; 361:1539-1547. 
8. Shlipak MG, Stehman-Breen C, Fried LF et al. The presence of frailty in elderly persons with chronic renal insufficiency. American Journal of Kidney Disease, 2004; 43:861-867.

9. Noble H \& Lewis, R. Approaches for people with progressive kidney disease: a non-dialytic pathway. In Palliative Care Nursing at a Glance, First Edition. Eds C. Ingleton and P. Larkin. 2016; John Wiley\& Sons, Ltd. UK. Pg. 70-72.

10. Davison SN, Levin A, Moss AH et al. Kidney Disease: Improving Global Outcomes. Executive summary of the KDIGO Controversies Conference on Supportive Care in Chronic Kidney Disease: developing a roadmap to improving quality care. Kidney International, 2015 Sep; 88(3):447-59.

11. Rockville, MD: The Renal Physicians Association. 2010. Shared decision-making in the appropriate initiation of and withdrawal from dialysis.

12. Murray AM, Arko C, Chen SC, Gilbertson DT, Moss AH: Use of hospice in the United States dialysis population. Clinical Journal of the American Society of Nephrology, 2006; 1: 12481255.

13. Roderick, $\mathrm{P}$, Rayner $\mathrm{H}$, Tonkin-Crine $\mathrm{S}$ et al. A national study of practice patterns in UK renal units in the use of dialysis and conservative kidney management to treat people aged 75 years and over with chronic kidney failure. Health Services and Delivery Research, 2015; 3(12): p. 1-186.

14. Noble HR, Agus A, Goodfellow N, et al. Palliative Care in chronic kidney disease: the PACKS study - quality of life, decision making, costs and impact on carers in people managed without dialysis. BMC Nephrology, 2015; 16:104.

15. Noble HR, Brazil K, Burns A et al. Clinician views of patient decisional conflict when deciding between dialysis and conservative management: Qualitative findings from the PAlliative Care in chronic Kidney diSease (PACKS) study. Palliative Medicine, 2017; Apr 1:269216317704625. doi: 10.1177/0269216317704625.

16. National Institute for Health and Care Excellence. Guide to the methods of technology appraisal 2013. NICE: London. 2013.

17. Curtis L \& Burns, A. (2016) Unit Costs of Health and Social Care 2016, Personal Social Services Research Unit, University of Kent, Canterbury.

18. Curtis L \& Burns, A. (2015) Unit Costs of Health and Social Care 2015, Personal Social Services Research Unit, University of Kent, Canterbury.

19. Herdman M, Gudex C, Lloyd A, Janssen MF, Kind P, Parkin D, Bonsel G, Badia X: Development and preliminary testing of the new five-level version of EQ-5D (EQ-5D-5 L). Qual Life Res. 2011;20:1727-1736.

20. van Hout B, Janssen MF, et al. Interim scoring for the EQ-5D-5L: Mapping the EQ-5D-5L to EQ-5D-3L value sets. Value in Health. 2012;15(5):708-15.

21. Cleemput I, Kesteloot K, Moons P et al. The Construct and Concurrent Validity of the EQ-5D in a Renal Transplant Population. Value in Health. 2004;7(4):499-509.

22. ISRCTN17133653

23. Clark MD, Higgins R, Gumber A et al. 'A Better Way to Measure Choices' Discrete Choice Experiment and Conjoint Analysis Studies in Nephrology: A Literature Review. EMJ Nephrology, 2013; 1, 52-59. 
PACKs Health Service Use Analysis 